\title{
EXPERIMENTAL CONGENITAL TOXOPLASMOSIS IN WISTAR AND HOLTZMAN RATS
}

\author{
PAULINO J.P. \& VITOR R.W.A.
}

\begin{abstract}
Summary :
Congenital toxoplasmosis was evaluated in Wistar and Holtzman rats using two strains of Toxoplasma gondii isolated in Brazil. Pregnant rats were inoculated by subcutaneous or intraperitoneal routes with $10^{6}$ or $8 \times 10^{6}$ tachyzoites of $\mathrm{N}$ strain /virulent for mice) and by subcutaneous or oral routes with $10^{2}$ or $1.2 \times 10^{3}$ cysts of $P$ strain (avirulent for mice). The tissues of rat pups born from these rats were bioassayed for $T$. gondii infection. T. gondii was not observed in the pups born from rats inoculated with $\mathrm{N}$ strain. In the animals inoculated with $\mathrm{P}$ strain, congenital toxoplasmosis occurred in $22.8 \%$ (Wistar rats inoculated with $10^{2}$ cysts by the subcutaneous route), $11.4 \%$ (Wistar rats inoculated with $10^{2}$ cysts by the oral route), $21.2 \%$ (Wistar rats inoculated with $1.2 \times 10^{3}$ cysts by the oral route) and $2.9 \%$ of fetal infection $\left(H o l t z m a n\right.$ rats inoculated with $10^{2}$ cysts by the oral route). None of the pups born from chronically infected mother were infected with $T$. gondii.
\end{abstract}

KEY WORDS : Toxoplasma gondii, congenital toxoplasmosis, rats.
Résumé : LA TOXOPLASMOSE CONGÉNITALE EXPÉRIMENTALE CHEZ LES RATS WISTAR ET HOLTZMAN

La toxoplasmose congénitale a été etudiée chez les rats Wistar et Holtzman en utilisant deux souches de Toxoplasma gondii isolées au Brésil. Les femelles gestantes ont été inoculées par les voies sous-cutanée et intra-péritonéale avec $10^{6}$ et $8 \times 10^{6}$ tachyzoïtes de la souche $N$ (virulente pour les souris) et par les voies souscutanée et orale avec $10^{2}$ et $1,2 \times 10^{3}$ kystes de la souche $P$ (non virulente pour les souris). Les tissus des nouveaux-nés de ces animaux ont été inoculés chez les souris pour la recherche de T. gondii. La transmission congénitale n'a pas été observée chez les animaux inoculés avec la souche $N$. Par contre, avec la souche $P, 22,8 \%$ d'infection fotale ont été observés chez les rates Wistar gestantes infectées avec $10^{2}$ kystes par voie sous cutanée, et aussi $11,4 \%$ et $21,2 \%$ d'infection fotale ont été observés après inoculation par voie orale avec $10^{2}$ et $1,2 \times 10^{3}$ kystes respectivement. Chez les femelles Holtzman infectées avec $10^{2}$ kystes par voie orale, le taux d'infection fortale de $2,9 \%$ a été obtenu. Les animaux nés lors de la phase chronique ont été sans contamination par T. gondii.

MOTS CLÉS : Toxoplasma gondii, toxoplasmose congénitale, rats.
T Toxoplasmosis is a coccidian infection caused by the obligate intracellular protozoan Toxoplasma gondii. For most immunocompetent individuals the infection is asymptomatic but severe toxoplasmosis can occur in immunocompromised patients and in infected fetuses in utero. The latter may be aborted or present neurological and ophthalmological disorders (Desmonts \& Couvreur, 1974). Congenital toxoplasmosis is also important in animals, because it is considered one of the major causes of abortion and neonatal losses in goats and sheep (Dubey \& Beattie, 1988).

The development of a suitable animal model of congenital toxoplasmosis is essential to evaluate the efficacy

Departamento de Parasitologia, Instituto de Ciencias Biologicas, Universidade Federal de Minas Gerais, Av. Antonio Carlos 6627, C.P. 486, Belo Horizonte, CEP 31.270-901, Brazil.

Correspondence: Ricardo W. A. Vitor. Tel: 0055-31-499-2875 - Fax: 0055-31-499-2970 - E-mail: vitorrwa@mono.icb.ufmg.br of vaccines and new drugs. Dubey \& Shen (1991), Zenner et al. (1993) and Dubey et al. (1997) have used rats as models in the study of congenital toxoplasmosis and have observed that congenital transmission only occurs in rats that are infected during pregnancy and that maternal chronic infection protects the pups against congenital toxoplasmosis. Zenner et al. (1993) observed that congenital toxoplasmosis occurred in Fisher rats infected with virulent $(\mathrm{RH})$ or avirulent (Prugniaud and 76K) strains of T. gondii. Dubey et al. (1997) observed that, unlike mice, repetition of congenital infection by $T$. gondii in successive generations of Sprague Dawley rats occur in less than $1 \%$ of cases. The purpose of this work was to study congenital toxoplasmosis in Wistar and Holtzman rats infected with a virulent $(\mathrm{N})$ and an avirulent $(\mathrm{P})$ strain of $T$. gondii isolated in Brazil, verifying the frequency of congenital transmission in rats infected during pregnancy and the possibility of occurrence of maternofetal transmission in reinfected rats during the chronic infection. 


\section{MATERIALS AND METHODS}

\section{ANIMALS}

$\mathrm{F}$ emale Wistar rats and female Holtzman rats three months old were used for mating. Swiss Webster mice were used for inoculation of rat fetal tissues (bioassay). All animals used in the experiment were obtained from CEBIO-Federal University of Minas Gerais (Belo Horizonte, Brazil) and were tested for the presence of $T$. gondii antibodies.

\section{STRAINS OF T. GONDII}

The $\mathrm{N}$ and $\mathrm{P}$ strains of $T$. gondii were used for the infection of the female rats. The $\mathrm{N}$ strain, isolated from a rabbit by Nobrega et al. (1952) is highly virulent for mice, causing $100 \%$ of mortality between ten and 15 days after the infection of these animals with one tachyzoite by the intraperitoneal route. This strain is maintained through successive passages of tachyzoites by the intraperitoneal route in mice every 4872 hours. The P strain was isolated from a dog by Jamra \& Vieira (1991) and is mildly virulent for mice, with $100 \%$ survival for 180 days after the infection of mice with ten cysts by the oral route. This strain is maintained by the oral inoculation of cysts in mice every six months.

\section{MATING AND INFECTION OF FEMALE RATS}

Three female rats of each strain were kept in separate cages with one $T$. gondii negative male of the respective strain during seven days for mating. After the period of mating, the female rats were housed in individual cages and grouped according to the inoculum. The infection of the animals was made on the 14th day after the beginning of mating, which corresponds to the period between the 7 th and 14 th days of pregnancy. Eight groups of animals (six rats per group) were infected with $T$. gondii as shown in Table I. One animal from group W1, W6, H1 and two animals from group W4, $\mathrm{H} 2$ did not give birth.

\section{REINFECTION OF THE FEMALE RATS}

The rats of the groups W3, W4, W5, W6, H1 and H2 were mated again between 60 and 80 days after primary infection and received the same inoculum between the 7 th and 14 th days of pregnancy by the same route of infection used initially.

\section{INVESTIGATION OF $T$. GONDII INFECTION IN FEMALE RATS}

The rats were bled from the orbital sinus before the infection and before the reinfection (30 or 60 days after primary infection) and their sera were tested for the presence of $T$. gondii-specific IgG antibodies by the Enzyme-Linked Immunosorbent Assay (ELISA) (Voller et al., 1976) and Indirect Immunofluorescence Assay (IFA) (Camargo, 1964). The rats were examined for $T$. gondii infection by microscopy of brain tissue cysts or by intraperitoneal subinoculation of brain into healthy mice.

\section{BIOSSAY}

For evidence of congenital transmission of pups that were born of infected rats with $T$. gondii during pregnancy the following protocol was used. After birth, the pups were killed between 0 and 12 days age and from each pup the lungs, heart and liver were removed. Tissues were homogenized in $1 \mathrm{ml}$ of phosphate buffered saline (PBS) $\mathrm{pH} 7.2$. One aliquots of $0.5 \mathrm{ml}$ of homogenate of tissues of each pup was intraperitoneally inoculated into one uninfected mouse. Thirty days after inoculation, the surviving recipient mice were bled from the orbital sinus and the sera obtained were tested for the presence of antibodies to $T$. gondii

\begin{tabular}{|c|c|c|c|c|c|}
\hline Groups & $\begin{array}{c}\text { Number } \\
\text { of } \\
\text { female rats }\end{array}$ & Inoculum & $\begin{array}{c}\text { Number of } \\
\text { female rats } \\
\text { that transmitted } \\
\text { the parasite }(\%)\end{array}$ & $\begin{array}{c}\text { Total } \\
\text { of } \\
\text { pups }\end{array}$ & $\begin{array}{c}\text { Number } \\
\text { of infected pups }\end{array}$ \\
\hline W1 & 05 & $10^{6} \mathrm{~N}$ strain tachyzoites-intraperitoneal route & $0(0)$ & 51 & $0(0)$ \\
\hline W2 & 06 & $10^{6} \mathrm{~N}$ strain tachyzoites-subcutaneous route & $0(0)$ & 63 & $0(0)$ \\
\hline W3 & 06 & $10^{2} \mathrm{P}$ strain cysts-subcutaneous route & $03(50)$ & 57 & $13(22.8)$ \\
\hline W4 & 04 & $10^{2} \mathrm{P}$ strain cysts-oral route & $02(50)$ & 35 & $04(11.4)$ \\
\hline W5 & 06 & $8 \times 10^{6} \mathrm{~N}$ strain tachyzoites-intraperitoneal route & $0(0)$ & 50 & $0(0)$ \\
\hline w6 & 05 & $1.2 \times 10^{3} \mathrm{P}$ strain cysts-oral route & $04(80)$ & 52 & $11(21.2)$ \\
\hline H1 & 05 & $10^{6} \mathrm{~N}$ strain tachyzoites-intraperitoneal route & $0(0)$ & 43 & $0(0)$ \\
\hline $\mathrm{H} 2$ & 04 & $10^{2} \mathrm{P}$ strain cysts-oral route & $01(25)$ & 35 & $01(2.9)$ \\
\hline
\end{tabular}

Table I. - Experimental congenital toxoplasmis in Wistar and Holtzman rats in acute stage of the infection inoculated with tachyzoites (N strain) and cysts (P strain) of Toxoplasma gondii between the 7 th and 14 th days of pregnancy. 
by ELISA and IFA. Moreover, the brains of these mice were removed for microscopic examination to verify the presence of cysts. Mice were considered T. gondii positive when tachyzoites were found in the peritoneal fluid, cysts were seen in the brain or antibodies were sought in their sera.

\section{LACTOGENIC TRANSMISSION OF T. GONDII}

To study transmission of $T$. gondii through milk, seven Wistar rats and three Holtzman rats serologically negative to T. gondii were inoculated immediately after the delivery with $1.2 \times 10^{3}$ and $10^{2}$ cysts of the P strain by the oral route, respectively. The pups suckled normally within a period of ten to 15 days. After this period, they were sacrificed and their lungs, heart and liver were homogenized in $1 \mathrm{ml}$ of PBS ( $\mathrm{pH}$ 7.2) and bioassayed in mice. The methodology used for detection of the parasite was the same used in the congenital transmission experiments.

\section{STATISTICAL ANALYSIS}

The significance of observed differences between groups of rats was assessed by the chi-square test $(p=0.05)$.

\section{RESULTS}

Whe frequency of congenital toxoplasmosis in Wistar and Holtzman rats infected with the $\mathrm{N}$ and $\mathrm{P}$ strains is summarized in Table I.

None of the pups born to dams inoculated with $\mathrm{N}$ strain (Groups W1, W2, W5 and H1) was infected with T. gondii. However, after infection with the $\mathrm{P}$ strain (Groups W3, W4, W6 and H2), it was observed that nine of the fifteen Wistar rats and one of the four Holtzman rats transmitted $T$. gondii to their pups. The frequency of congenital transmission in the groups W3, W4, W6 and $\mathrm{H} 2$ was $22.8 \%, 11.4 \%, 21.2 \%$ and $2.9 \%$, respectively. The results obtained demonstrated differences in the frequency of congenital toxoplasmosis in Wistar rats (Group W4) compared to Holtzman rats (Group H2) inoculated by the same route and with the same quantity of parasites. In the same way there were observed differences in the frequency of congenital toxoplasmosis in rats inoculated by the subcutaneous route (Group W3) compared with the oral route (Group W4) and in rats infected with $1.2 \times 10^{3}$ cysts (Group W6) and $10^{2}$ cysts (Group W4). Nevertheless, these differences were not statistically significant.

None of the rats reinfected during the second pregnancy transmitted the parasite to their pups.

ELISA (Mean absorbance) and IFA ( $\geq 1: 2.048)$ results revealed that all the female rats were infected after the first inoculum. Tissue cysts were observed in the brain of female rats inoculated with the $\mathrm{P}$ strain, but not with the $\mathrm{N}$ strain.

There was no transmission of $T$. gondii through milk in any of the 50 pups of Wistar rats inoculated with $1.2 \times 10^{3}$ cysts of the $\mathrm{P}$ strain by the oral route, like in 23 pups of Holtzman rats inoculated with $10^{2}$ cysts of the P strain by the oral route.

\section{DISCUSSION}

厂 $\mathrm{n}$ pregnant rats inoculated with tachyzoites of the $\mathrm{N}$ strain (highly virulent for mice), no case of congenital transmission was observed, whatever the rat strain (Wistar or Holtzman), the quantity of parasites $\left(10^{6}\right.$ or $8 \times 10^{6}$ tachyzoites) and the route of inoculation (intraperitoneal or subcutaneous). In literature, there are no reports of strains of $T$. gondii that do not produce congenital infection in rats that received the primoinfection during pregnancy. Thiermann (1957), Remington et al. (1961) and Zenner et al. (1993) observed rats that received the primoinfection during pregnancy with tachyzoites of $T$. gondii strains, which have similar behavior to $\mathrm{N}$ strain, transmitted the parasite to their pups. Zenner et al. (1993) obtained $58.2 \%$ of transmission using $8 \times 10^{6} \mathrm{RH}$ strain tachyzoites, while in the present work, with the use of $10^{6}$ or $8 \times 10^{6}$ tachyzoites of $\mathrm{N}$ strain, no case of congenital transmission was observed. It is possible that some pups sacrificed later might have been infected by the congenital route with $\mathrm{N}$ strain, however the infection was already eliminated at the moment of the bioassay. T. gondii was not isolated from brain of rats infected with the virulent $\mathrm{N}$ strain, although antibody response suggests active infection. Cystogenesis was not observed, indicating cystogenic incapacity of $\mathrm{N}$ strain in Wistar and Holtzman rats.

The congenital transmission of the parasite occurred in all the primoinfected groups, whose rats were infected with cysts of the P strain during pregnancy. The transmission occurred either in Wistar rats or in Holtzman rats, whatever of the route of inoculation (subcutaneous or oral) and the number of parasites $\left(10^{2}\right.$ or $1.2 \times 10^{3}$ cysts). In the present work it was used the same quantity of cysts of the P strain as determined by Zenner et al. (1993) with 76K and Prugniaud strains. However, these authors observed a rate of transmission of $35.2 \%$ and $62.8 \%$ respectively compared to $21.2 \%$ in Wistar rats. Zenner et al. (1993) observed that all the rats infected with $76 \mathrm{~K}$ and Prugniaud strains transmitted the parasite to their pups, while only $80 \%$ of the rats inoculated with $1.2 \times 10^{3}$ cysts of the P strain were able to transmit the parasite. Probably, the $76 \mathrm{~K}$ and Prugniaud strains are more invasive than the $\mathrm{P}$ strain, decreasing the time of spreading until reaching 
the fetal tissues. Also, it is probable that different strains of rats such as Fischer rats used by Zenner et al. (1993) show different susceptibility to $T$. gondii considering the low frequency of congenital transmission observed in Holtzman and Wistar rats. Probably, if, in our work, the brain had been included in the pool of organs used in the bioassay, the frequency of congenital transmission could have been higher. It may be possible that the pups that were sacrificed 12 days after birth had brain cysts and rare parasites in the lung, heart and live already. Bioassay using fetus homogenate according to Zenner et al. (1993) will probably increase the rate of transmission observed in our experiments.

No rats of the groups W3, W4, W5, W6, H1 and H2 reinfected during the second pregnancy transmitted the parasite to their pups. Similarly to this study, Thiermann (1957) with the Santiago and St./P1 strains, Remington et al. (1961) with the RH and S6 strains, Dubey \& Shen (1991) and Zenner et al. (1993) did not find congenital transmission of the parasite from chronically infected rats either. However, Thiermann (1957) with the C.M strain, Remington et al. (1958) with RH strain, Remington et al. (1961) with the Beverley strain and Dubey et al. (1997) observed a low rate of congenital transmission in pups born from chronically infected mothers (for review, see Dubey \& Frenkel, 1998).

Johnson (1997) recently hypothesized that life cycle of T. gondii can be maintained solely by vertical route. However, in our studies, vertical or lactogenic transmission of the virulent $\mathrm{N}$ strain was not observed in Wistar and Holtzman rats. These results suggest that the natural life for the virulent strains of $T$. gondii hypothesized by Johnson (1997) is not applicable for all the rats or $T$. gondii lineage.

The results obtained permit to conclude that congenital transmission depends on the strain of $T$. gondii used to infect female Wistar and Holtzman rats and the period of the maternal infection. Therefore, this experimental model can be used to evaluate the methods of antenatal diagnosis and test chemotherapeutic agents and vaccines.

\section{ACKNOWLEDGEMENTS}

W e thank José Luiz de Faria and Rosalida Estevam Nazar Lopes for technical assistance. This study was supported by Fundacao de Amparo a Pesquisa do Estado de Minas Gerais (FAPEMIG).

\section{REFERENCES}

CAmargo M.E. Estudo comparativo das reacoes de Sabin Feldman e de Imunofluorescencia Indireta para a toxoplasmose em 1.000 soros humanos, comportamento anomalo de alguns soros. Revista do Instituto Adolfo Lutz, $1964,24,1-26$.

Desmonts G. \& Couvreur J. Congenital toxoplasmosis. A prospective study of 378 pregnancies. The New England Journal of Medicine, 1974, 290, 1110-1116.

Dubey J.P. \& BeATtie C.P. Toxoplasmosis of Animals and Man, CRC Press, Boca Raton, Florida, 1988, 220.

DubeY J.P. \& SHen S.K. Rat model of congenital toxoplasmosis. Infection and Immunity, 1991, 59, 3301-3302

Dubey J.P., Shen S.K., Kwok O.C.H. \& Thulliez P. Toxoplasmosis in rats (Rattus norvegicus): congenital transmission to first and second generation offspring and isolation of Toxoplasma gondii from seronegative rats. Parasitology, 1997, 115, 9-14

DuBEY J.P. \& Frenkel J.K. Toxoplasmosis of rats: a review, with considerations of their value as an animal model and their possible role in epidemiology. Veterinary Parasitology, 1998, 77, 1-32.

JAMRA L.M.F. \& VIEIRA M.P.L. Isolamento do Toxoplasma gondii de exsudato peritoneal e orgaos de camundongos com infeccao experimental. Revista do Instituto de Medicina Tropical de Sao Paulo, 1991, 33, 435-441.

Johnson A.M. Speculation on possible life cycles for the clonal lineages in the genus Toxoplasma. Parasitology Today, 1997, 13, 393-397.

Nobrega P., Trapp E. \& Giovannoni M. Toxoplasmose epizótica em coelhos. I Ação da sulfadiazina. Ciência e Cultura, 1952, 4, 134-135.

Remington J.S., Jacobs L. \& Kaufman H.E. Studies on chronic toxoplasmosis. The relation of infective dose to residual infection and to the possibility of congenital transmission. American Journal of Ophthalmology, 1958, 46, 261-267.

Remington J.S., JaCobS L. \& Melton M.L. Congenital transmission of toxoplasmosis from mother animals with acute and chronic infections. Journal of Infectious Diseases, 1961, 108, 163-173.

ThIERMAnN I.E. Transmission congenita del Toxoplasma gondii en ratas con infeccion leve. Biologica (Santiago), 1957, 23, 59-67.

Voller A., Bidwell D.E. \& Bartlet A. Enzyme immunoassays in diagnostic medicine. Theory and practice. Bulletin of the World Health Organization, 1976, 53, 55-65.

Zenner L., Darcy F., Cesbron-Delauw M. F. \& Capron A. Rat model of congenital toxoplasmosis: rate of transmission of three Toxoplasma gondii strains to fetuses and protective effect of a chronic infection. Infection and Immunity, 1993, 61, 360-363.

Reçu le 28 juillet 1998 Accepté le 29 octobre 1998 